\title{
O perigo está no ar: será que a "espanhola" volta?
}

\author{
Danger is in the air: is the Spanish Flu back?
}

Entrevista com/Interview with

\section{Marilda Mendonça Siqueira}

Pesquisadora do Laboratório de Vírus Respiratórios e Sarampo Fundação Oswaldo Cruz

Av. Brasil 4365

21045-900 Rio de Janeiro -

RJ - Brasil

mmsiq@ioc.fiocruz.br

Concedida a/Interview given to Jaime Larry Benchimol, Roberta Cardoso Cerqueira e Ruth B. Martins

Equipe de História, Ciências, Saúde - Manguinhos hscience@coc.fiocruz.br
SIQUEIRA, M. M.: O perigo está no ar: será que a "espanhola" volta? Entrevista concedida a Benchimol, J. L., Cerqueira, R. C. e Martins, R. B.

História, Ciências, Saúde - Manguinhos, v. 12, n. 1, p. 159-68, jan.-abr. 2005.

Enquanto preparávamos este número da revista, em que têm destaque três artigos sobre a gripe espanhola, aquela que varreu o mundo em 1918, matando, ao que parece, mais gente que a Primeira Guerra Mundial, notícias publicadas nos jornais atuais nos deixavam temerosos: "O mundo está muito perto da pandemia de gripe", afirmava a Organização Mundial de Saúde em 20 de janeiro do corrente ano (O Globo, 1.2.2005, p. 28). Na edição de 15 de março do mesmo jornal (p. 34), outra matéria destacava: "Especialistas alertam que pandemia de gripe das aves seria devastadora". Como temos o privilégio de ser vizinhos de uma dessas especialistas, fomos perguntar a ela o quanto disso é verdade. Compartilhamos, então, com os leitores, a conversa com a virologista Marilda Mendonça Siqueira, pesquisadora do Departamento de Virologia da Fundação Oswaldo Cruz e responsável pelo Laboratório de Vírus Respiratórios e Sarampo, integrante da rede internacional de vigilância de influenza da Organização Mundial de Saúde (OMS) desde a década de 1950.

PALAVRAS-CHAVE: gripe espanhola; gripe de aves; vírus; influenza; infecções respiratórias; pandemia de gripe.

SIQUEIRA, M. M.: Danger is in the air: is the Spanish Flu back? Interview given to Benchimol, J. L., Cerqueira, R. C. and Martins, R. B.

História, Ciências, Saúde - Manguinhos, v. 12, n. 1, p. 159-68, Jan.-Apr. 2005.

When we were working on the present issue of our journal, where there are three special articles on the Spanish Flu, the epidemic that broke out in 1918 supposedly killing more people than the First World War, some news in the papers made our hair stand on end. "The world is heading to an influenza pan-epidemic", announced the World Health Organization last January 20 (O Globo, 2.01.2005, p.28). In the March 15 issue of the same newspaper, one reads: "Specialists warn that the effects of the pan-epidemic of fowl flu would be devastating". As we are privileged to have one of these specialists here in Fundação Oswaldo Cruz, we asked her to what extend these statements were true. So, we are now sharing with you readers the enlightening conversation we had with Marilda Mendonça Siqueira. She is researcher of Fundação Oswaldo Cruz Virology Department, where she leads the Respiratory Viruses and Measles Lab, part of WHO's international net for influenza vigilance, which has existed since the 1950 's.

KEYWORDS: Spanish flu; fowl flu; virus; influenza; respiratory infection; flu pan-epidemic. 
Estamos preparando um número da revista que vai ter um dossiê sobre gripe espanhola e, aí como nosso público está um pouco alheio à discussão que vocês estão travando, estamos curiosos e queremos informar a nossos leitores o que está por trás das notícias alarmantes que estão saindo na imprensa sobre a eminente chegada da gripe aviária no Brasil. O quê você está fazendo? Fale-nos sobre a comissão criada pelo Ministério da Saúde, sobre o que vem sendo feito... como é isso?

Primeiro vou falar alguma coisa sobre a influenza. Alguns dos vírus conhecidos podem sofrer mudanças em suas características de ano a ano. Um deles é o vírus da influenza, um dos mais estudados, até por isso mesmo. Em sua superfície tem duas proteínas: uma é chamada hemaglutinina e outra neuraminidase. Elas mudam, porque muda o genoma, e faz por uma série de fatores. Os organismos têm um genoma que normalmente é um segmento único. No vírus da influenza, ele é particulado. São oito pedaços, cada um codificando, dando origem a determinada proteína. Quando um organismo tem um genoma com pedaços, o que acontece? Se ele interage dentro de um hospedeiro com outro vírus, é mais fácil para ele "trocar" segmentos do genoma. É diferente quando se trata de um organismo com genoma inteiro: para trocar o pedaço, o segmento dele, tem que haver uma enzima em determinada altura que corta, outra que põe lá e encaixa, ainda outra que vai lá e cola, entenderam? É mais complicado de acontecer. Então o vírus de influenza tem esse genoma particulado que favorece o rearranjo genômico. Além disso, apresenta uma outra característica: mesmo não trocando pedaços inteiros de genoma, todos os anos, nele podem ocorrer pequenas, pontuais mudanças.

A vacina contra influenza tem de ser tomada todos os anos por causa das mudanças que fazem com que, de um ano para outro, o vírus da influenza não seja exatamente igual nessas proteínas de superfície. Se você tomar uma vacina contra a pólio ou o sarampo, está protegido para a vida inteira. Influenza, não. Primeiro, a imunidade que a vacina dá dura apenas uns oito meses. Depois, como expliquei, o vírus muda de um ano para outro, porque mudar em pequenos pedacinhos, o vírus deste ano pode ser um pouquinho diferente do vírus do ano passado.

A proteção vacinal vai sendo calibrada todo ano?

É. Em 1947, a Organização Mundial de Saúde (OMS) começou a organizar uma rede, atualmente composta por 115 laboratórios composta em 85 países. No Brasil somos três laboratórios de referência da Organização Mundial de Saúde: o nosso aqui da Fiocruz, e os dos institutos Evandro Chagas, em Belém, e Adolpho Lutz, em São Paulo. Como é que a gente trabalha? Coletamos amostras clínicas de pessoas que apresentam infecção respiratória aguda durante o ano todo. No Rio de Janeiro temos dois postos de coleta 
de pessoas que chegam com esta síndrome aguda. Quando identificamos o vírus da influenza, o estudamos para ver se a característica dele é igual à do ano passado e, se não é, como está se comportando. E a gente está observando, ao longo dos anos, as mudanças que ocorrem em seu genoma.

Marilda, você provavelmente detecta várias mudanças diferentes num mesmo período, não?

O que fazemos é verificar mudanças que possam ocorrer nestas proteínas; sendo a mais importante delas a hemaglutinina. Há vários tipos de hemaglutinina. Desde 1976 circulam duas, chamadas de $\mathrm{H} 3$ e H1. Estamos verificando as mudanças que as epidemias anuais provocam nessas hemaglutininas. A gente identifica essas mudanças no vírus e envia as informações para a OMS. Baseados nas informações que recebe dos laboratórios espalhados pelo mundo, a OMS faz duas reuniões por ano, uma em fevereiro, com o pessoal do Hemisfério Norte, outra em setembro, com o pessoal do Hemisfério Sul. Todos os anos a OMS faz isso. Nessas reuniões verifica quais são as cepas predominantes em cada Hemisfério e em seguida informa aos fabricantes de vacinas quais são as cepas que devem ser utilizadas na vacina. As indústrias privadas multinacionais produzem as vacinas de acordo com cepas de vírus que a OMS estabeleceu junto com sua rede de laboratórios. A produção da vacina é um problema porque demora uns oito meses. Não é como aquela contra o sarampo, que Bio-Manguinhos pode estocar. Pode mudar a sua composição todos os anos. A reunião é feita em setembro, e o produtor tem que estar com a vacina pronta em fevereiro do ano seguinte, porque ainda se tem de fazer o controle de qualidade para depois distribuí-la às populações, dos diferentes países.

Se a reunião com os laboratórios é em setembro e a vacina tem que estar na rua em fevereiro, passam-se quatro meses apenas. Parece que falta tempo para produzir o novo lote?

Normalmente o fabricante tem um prazo de até oito meses, e ele demora de seis a oito meses para fabricar a nova vacina. Você vê: setembro, outubro, novembro, dezembro, janeiro e fevereiro - são seis meses que ele tem para conseguir a vacina. Quando a indicação do novo vírus chega ao laboratório, o fabricante tem de operacionalizar a produção. Ele tem um mês para fazer crescer o vírus e... às vezes não crescem títulos suficientes para a produção de uma vacina; é preciso voltar à cepa anterior. Isso aconteceu em 1999. Mudou a cepa, só que nenhum fabricante conseguiu viabilizar a produção. Alguns vírus têm mais dificuldade para se reproduzir em laboratórios. 
A gente compra vacina de fora ou fabrica no Brasil?

A produção da vacina contra a gripe foi uma decisão do Ministério da Saúde. Vai ser feita no Instituto Butantan. Haverá uma planta. Uma concorrência teve lugar, venceram algumas empresas para fazer um laboratório destinado à fabricação da vacina contra a influenza. O prazo é de três anos para que a fábrica esteja pronta. Por enquanto, o Butantan compra a vacina fora do país e a envasa.

O problema é que nós sabemos que alguns desses Hemaglutininas (Hs) têm um potencial muito grande para provocar uma pandemia. O H5, por exemplo, esse vírus da influenza aviária que está circulando na Ásia. A preocupação é muito grande porque já foi encontrado no Vietnã, Camboja, Tailândia... Dos 88 casos identificados, de pessoas que se contaminaram com o vírus que vem da ave para o homem, 51 já morreram. A taxa de letalidade é muito alta. Nossa sorte é que o sistema mundial de saúde, por enquanto, está sendo capaz de verificar caso a caso. $\mathrm{O}$ vírus passou do animal - de uma ave - para o homem diretamente, mas ainda não foi capaz de passar de um homem para outro. Normalmente, quando um vírus migra de uma espécie para uma outra, decorre um tempo de adaptação até que ele consiga ser transmitido entre os novos hospedeiros.

Mas na Ásia já houve um caso, não houve, de transmissão de homem a homem?

Desse H5 tem um caso suspeito, mas não foi confirmado ainda. A OMS está muito preocupada porque a transmissão ocorre pelas vias respiratórias, por intermédio de gotículas de secreção. Numa sala como esta aqui, com ar condicionado, as taxas de infecção são altíssimas. Ninguém na população, nenhum ser humano tem anticorpo ao $\mathrm{H} 5$, o que significa que a letalidade também será altíssima.

Quais são os sintomas? A doença afeta o sistema respiratório?

Pode atacar outros órgãos, mas, basicamente, dá uma pneumonia gravíssima, muito letal.

Nesse tom, li outro dia uma notícia da Inglaterra, se bem me lembro. Os agentes sanitários consideraram muito alta a probabilidade deste vírus se propagar lá a curto prazo. Você concorda com isso?

Não sei se podemos dizer a curto prazo. É difícil prever. O que conhecemos do vírus influenza são as pandemias históricas, extremamente importantes, como a de 1918-19, que matou mais gente do que a Segunda Guerra Mundial. Alguns livros dizem que morreram vinte milhões de pessoas, outros pesquisadores dizem que foram quarenta milhões. Aqui no Rio de Janeiro, no cemitério do Caju, tem muitos túmulos de pessoas que morreram da gripe espa- 
nhola. Ainda não temos boas estatísticas hoje, como é que teríamos em 1918? De qualquer maneira, hoje temos outro cenário, porque o mundo todo está alerta. A Organização Mundial de Saúde está estudando caso a caso. Mataram não sei quantos milhões de aves em alguns países asiáticos. Há uma cooperação entre os países em torno desse problema.

Um sanitarista do escritório da OMS na Ásia declarava, preocupado, em uma matéria veiculada por agências de notícias em março, que os países ricos tinham de tomar providências enérgicas. Que tipo de medidas preventivas o Brasil vem tomando? Se chegar aqui um doente, o que se faz?

A primeira coisa a fazer é isolar o paciente e todos os que tiveram contato com ele. Nós fizemos isso há dois anos, naquela epidemia de SARS (Síndrome Aguda Respiratória Severa), com os casos suspeitos que chegaram ao Brasil. Nenhum foi confirmado, graças a Deus! Quem chegou aqui com alguma suspeita saía direto do avião para um hospital. Tem que ser assim, uma medida enérgica, porque infecção respiratória não se segura de outra maneira.

Vamos supor que esses vaticínios se realizem... e a coisa se transforme de fato numa pandemia. O quê que tem de proteção real, efetiva?

Não tem. A OMS produziu o chamado Plano de Contenção para uma Possível Pandemia de Influenza (http://www.paho.org/ portuguese/gov/ce/ce132-fr-p.pdf). Todos os países têm de preparar o seu. O da OMS é um plano geral; é claro que o dos Estados Unidos não serve para o Vietnã, e nem o do Vietnã serve para Uganda. Cada país faz as adaptações de acordo com a sua realidade.

E esse plano é complexo, tem várias fases, etapa 0, itens 01, 02 e assim por diante, detalhando-se o que vai acontecer em cada uma. A Secretaria de Vigilância em Saúde, do Ministério da Saúde brasileiro, montou um grupo de técnicos com a finalidade de criar um plano que proteja nossa população. Um dos parceiros da iniciativa é meu laboratório, o de Vírus Respiratórios e Sarampo do Instituto Oswaldo Cruz (IOC), que integra a rede internacional de vigilância de influenza da Organização Mundial de Saúde (OMS) desde a década de 1950.

O plano vem sendo elaborado por uma equipe multidisciplinar. Há profissionais do laboratório, de vigilância epidemiológica, vigilância hospitalar, das áreas de medicamentos e vacinas, participam Biomanguinhos, Farmanguinhos, Butantan, tem ainda o pessoal de comunicação, há a parte clínica, com o Instituto de Pesquisas Evandro Chagas (Ipec).

No plano da OMS cada etapa já está estabelecida. Vamos supor: o que é uma pré-pandemia? O que um país precisa ter nessa etapa? Tem de ter rede de laboratório? Fase 1, o vírus está no Vietnã. $\mathrm{O}$ que a gente tem de fazer? Portos, aeroportos, laboratório, hospi- 
tal... Fase 2, o vírus chegou no Brasil; fase 3, passou, está contaminando; fase 4, a pandemia foi declarada. Tudo isso a gente está estudando, parte à parte. Por exemplo: nós não vamos ter vacina para todo mundo. Por que? Naturalmente os países ricos não vão vender vacina para a gente, vão se vacinar primeiro. Medicamento? Só tem um que atua efetivamente no combate ao influenza H5. Não vamos ter para todo mundo. Os países ricos vão produzir primeiro para eles.

Estamos fazendo projeções dessa ordem: quais são os grupos prioritários para tomar a vacina? Não podemos esperar a pandemia para então decidir. Quem vamos vacinar? Qual faixa etária? Um comitê desses é multidisciplinar. Apesar de ser pequeno, está formando sub-comitês, porque é um plano muito abrangente. Nesse momento, dos vinte e sete estados brasileiros, quinze fazem o diagnóstico da influenza. Não fazem do $\mathrm{H} 5$, mas sim dos vírus $\mathrm{H} 3$ e o H1 que estão circulando no momento. Um dos problemas, então, é treinar mais profissionais dos outros estados. Ficamos discutindo como operacionalizar isso tudo da maneira mais racional e prática. Não vamos achar que o Brasil vai ter um plano lindo, maravilhoso, mas totalmente inviável economicamente. Então, o problema é como, dentro de nossas possibilidades, fazer um plano prático e que proteja ao máximo a população. Isso não é fácil, porque se ocorrer uma pandemia, serão necessárias mudanças comportamentais grandes na sociedade, o que não se obtêm com decreto. Você controla se todo mundo cooperar. Em minha opinião, será preciso fechar escolas, shopping-centers. Não pode mais circular pessoas em lugares fechados. Agora, como é que você vai chegar para um shopping center e falar: "vai fechar por dois meses!" Não é fácil. Por trás de cada recomendação há uma série de implicações sociais e econômicas e elas afetam profundamente a vida das pessoas.

Os especialistas têm algum tipo de expectativa concreta de quando é que vai ocorrer?

Não. A gente sabe que pode ocorrer, e trabalha para que não ocorra. Nesse momento, a OMS está com equipes no Vietnã, no Camboja, trabalhando direto. Um trabalho muito político, nada fácil.

Os profissionais da área de saúde precisam ser imediatamente imunizados.

É, o pessoal de saúde, as forças armadas, há alguns outros grupos prioritários. O plano está sendo elaborado. Depois, ele vai para as várias sociedades, de infectologia, pediatria etc., para se ter suas sugestões e o aval. Ninguém faz um plano desses rapidamente. $\mathrm{O}$ Canadá demorou sete anos e se você entrar no site do Ministério da 
Saúde daquele país (http://www.hc-sc.gc.ca/), encontrará a informação de que o plano ainda está em elaboração, claro! Eles vão mudando, ajeitando, aperfeiçoando.

Vocês têm feito esses encontros para a elaboração do plano com que periodicidade?

Não com muita periodicidade. Neste ano já participamos de um e vamos continuar trabalhando via Internet.

Outros países além do Canadá têm esse plano disponível?

Até o momento trinta e seis países comunicaram à OMS que têm o seu plano, e vinte e cinco já fizeram sua apresentação. O do Canadá está na Internet, o dos Estados Unidos provavelmente também.

Tem um calendário estabelecido pela OMS para esses planos?

A OMS pede o envio deste plano o mais rápido possível.

Qual a característica do vírus do SARS que o torna tão diferente?

$\mathrm{O}$ vírus do SARS é um corona-vírus. Sua via principal de replicação é o trato gastrointestinal. Primeiramente, a transmissão ocorre pelas vias aéreas superiores mas a replicação maior se dá no trato gastrointestinal, e o vírus é eliminado pelas fezes também. Já o vírus influenza é essencialmente respiratório, cada vez que você espirrar, lá se vão milhões de partículas virais.

Na época da SARS preparamos com a OMS, em um mês, um manual de procedimentos.

Chegou ser distribuído esse manual?

Foi distribuído a todas as secretarias de saúde, claro, e a vários hospitais de referência. Foi criada uma rede de referência. Enfim, foi uma correria, um teste para ver o quanto a gente estava frágil, principalmente na rede hospitalar, na questão de leitos.

Há historiadores e sociólogos nesse grupo de trabalho?

Não, e seria interessante que houvesse. Quando vou a Londres, gosto de visitar nas livrarias a seção de história médica. É maravilhosa. O que tem de publicação sobre gripe espanhola, você não acredita. Edições fantásticas. A gente está defasada nessa área...

Na realidade, os meios de comunicação trabalham em cima da tragédia, do negativo, porque é isso que vende jornal. Eles só mostram o caos da saúde na cidade do Rio de Janeiro. Não estou dizendo que está uma maravilha, mas existem muitos progressos, muito investimento feito, como, por exemplo, nos programas de imunização. No Brasil, são um espetáculo! A OMS já conseguiu erradicar varíola, pólio, estamos erradicando sarampo, é um trabalho que 
envolve vários setores da saúde pública, da rede hospitalar, da rede de laboratórios, todos trabalhando arduamente. Na semana retrasada, vieram aqui profissionais de dez estados para fazer treinamento em sarampo e rubéola.

Vamos ter agora três reuniões macro-regionais sobre essas doenças. Tem que investigar, notificar, verificar caso a caso para se poder afirmar que a doença foi erradicada. E isso a população desconhece, não temos nem endemia. Mas isso não é valorizado pela mídia do país, a população não tem conhecimento, o que é uma pena. Apesar de ser extremamente problemático para o Ministério da Saúde e será sempre, porque nossa população é doente, pobre, muito mal alimentada - apesar disso, temos avanços que nunca são mostrados. Prevalece sempre aquele conceito muito negativo.

\section{Comoé sua equipe na Fiocruz?}

Somos doze pessoas aqui. Não são todos contratados pela Fiocruz, tem vários estudantes. Todos virologistas. Trabalhamos com vários vírus, porque os que causam infecções respiratórias não são só o influenza, tem o vírus sincicial respiratório, o principal agente etiológico de bronquiolite em crianças menores de dois anos de idade. Se você quiser saber se está circulando, a partir de abril, maio, é só chegar na fila de emergência de qualquer hospital, qualquer emergência, e encontrará mães que falam: "o peito do meu filho está chiando!" Profissionais do nosso laboratório trabalham com este vírus e com o adenovírus, em projetos com outras instituições de pesquisa do nosso país. Além disso, aqui é o Centro de Referência Nacional do Brasil e da OMS em sarampo e rubéola. Doze pessoas pode parecer um número grande, mas trabalhamos com pelo menos sete vírus.

Quais são os sintomas do novo vírus da gripe?

O influenza em geral dá febre alta, mal estar geral e uma coriza, uma secreção que não é muito purulenta - essa é uma característica -, uma secreção meio clara. Isso é quando o vírus faz um quadro de infecção das vias aéreas superiores. Quando atinge os pulmões, o quadro é típico de pneumonia. A maior parte de pneumonias provocadas por esses vírus influenza que estão circulando agora, o H3 e o H1, são provocadas por bactérias, as infecções bacterianas secundárias. O que está acontecendo com esse H5, com os casos que foram a óbito? O agente responsável pela pneumonia foi o próprio vírus. As pessoas estão desenvolvendo uma pneumonia em menos de 24 horas.

Por que as aves são os principais hospedeiros desses vírus?

$O$ vírus influenza tem um aspecto interessante: ele pode circular em animais. $\mathrm{O}$ do sarampo, por exemplo, é transmitido de homem 
a homem, e fica ali entre eles. O influenza, não. Seu principal hospedeiro são as aves, principalmente as aquáticas. Todas as hemaglutininas e neuraminidases descritas até o momento foram encontradas em aves aquáticas. Por isso, até um tempo atrás, quando se falava de influenza, vinha à mente aquela imagem do passarinho voando, fugindo do inverno do Hemisfério Norte para o Hemisfério Sul, e carreando o vírus para cá. Depois, no inverno daqui, voltar para o Hemisfério Norte. São as aves migratórias. Atualmente, sabemos que não precisa de uma ave migratória para fazer a transmissão. Os aviões transportam milhões de pessoas diariamente. É muito mais fácil do que pássaros voando por aí. No entanto, não deixaram de ser importantes, tanto assim que alguns projetos do Ministério da Agricultura dedicam-se à coleta de fezes de aves migratórias, para ver quais vírus influenza essas aves estão levando de um lado para outro. Algumas ilhas do Brasil - a Coroa do Avião em Pernambuco, outra ilha na Lagoa dos Patos, no Rio Grande do Sul, por exemplo - são pontos usados por aves migratórias.

\section{E a alimentação?}

Pode ser também pela alimentação. Pelas fezes ou alimentação. Comer carne pouco cozida aumenta muito essa chance.

Essa gripes que pegamos desde pequenos, são os homens os hospedeiros dela?

Sim, e é bom lembrar que vários outros vírus causam infecção respiratória que chamamos de gripe.

Se já conhecemos o vírus que pode ser o agente de uma grande pandemia, e já se tem uma estrutura de produção de vacinas, não se pode ter a vacina para ele?

Pode. Alguns países já estão começando a fazer isso. O problema é que essa vacina é um pouco diferente. Normalmente, para a produção de vacinas o vírus é inoculado em ovo embrionado. Costuma ser um ovo para uma dose de vacina. Depois de alguns dias, recolhe o fluido amniótico que tem no ovo embrionado e, por meio de uma série de processos, destrói o vírus. O vírus assim inativado, não tem como infectar uma pessoa e provocar a doença. Se é um vírus particulado, não consegue mais se reproduzir em lugar nenhum. Só que o H5 é tão patogênico que, na hora em que você infecta o ovo embrionado, ele mata o embrião. Para fazer a vacina é preciso usar um vírus feito por engenharia genética, muito caro. Já tem um paper publicado nos Estados Unidos em que o pesquisador diz como se faz. O problema é que você precisa de uma tecnologia muito sofisticada para produzir essa vacina, não pode num laboratório de segurança dois, como faz com o influenza. Para 
o H5, o início da produção tem de ser em nível de segurança quatro. É complicado imaginar países como o nosso a investir milhões na produção de uma vacina que não se sabe se vai ser utilizada. Como estocar essa vacina caríssima? Milhões de doses para se defender de uma coisa que não está acontecendo ainda. Politicamente é muito complicado.

Como é que você imagina uma pandemia com esse quadro de assistência hospitalar no Rio de Janeiro?

É melhor nem imaginar. Seria o caos total!

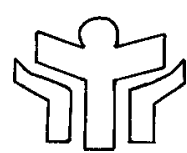

